\title{
Corneal Cross-Linking for the Treatment of Keratoconus in a Patient with Ipsilateral Myelinated Retinal Nerve Fiber Layer
}

\author{
M. Leozappa S. Ciani T. Micelli Ferrari \\ UOC Oculistica, Ospedale Generale Regionale 'F. Miulli', Acquaviva delle Fonti, \\ Italy
}

\section{Key Words}

Keratoconus $\cdot$ Cross-linking $\cdot$ Myelinated retinal nerve fiber layer

\begin{abstract}
Keratoconus associated with myelinated retinal nerve fibers is not frequent and the relationship between the two pathologies is difficult to explain, therefore studies and further investigation are required. The etiology of each condition may suggest the role of genetic factors. Follow-up is important to evaluate the progression of keratoconus and myelination. Here we describe the unusual coexistence of keratoconus and ipsilateral myelinated retinal nerve fiber layer and, for the first time, the corneal cross-linking treatment in this condition.
\end{abstract}

\section{Introduction}

Keratoconus is an idiopathic, progressive, non-inflammatory ectasia of the lower central cornea [1]. The prevalence of keratoconus ranges from 50 to 230 in 100,000 [2]. Its cause is unknown, although metabolic/chemical changes have been documented [3, 4]. Genetic factors may play an important role, as indicated by the association of keratoconus with genetic syndromes and gene mapping studies [5-9].

Keratoconus has been associated with macular coloboma [10], Leber's congenital amaurosis [11], retinal aplasia [12], cone-rod dystrophy [13], central serous chorioretinopathy [14], and rarely myelinated retinal nerve fibers [15]. Myelination, which occurs in $1 \%$ of the population $[16,17]$, normally terminates shortly after birth at the level of the lamina cribrosa. It seems to be due to anomalous distribution of oligodendroglia within the retina [17]. Retinal myelination is observed as an 
asymptomatic, isolated finding following routine examination. It is usually non-progressive, although there are two cases in which progression has been confirmed $[18,19]$.

\section{Case Report}

A 39-year-old woman presented with a diagnosis of stage II keratoconus in the right eye and stage I keratoconus in the left eye. The patient, characterized by eutocic childbirth, was on no general or local medication and had no history of any systemic illness or trauma, except for the detection of peripapillary myelinated retinal nerve fibers and amblyopia in her right eye during childhood. Medical history was negative for eye rubbing and/or allergic conjunctivitis.

Her best corrected visual acuity was $20 / 30$ in the right eye, with refractive error of $-1.50-2.50 \times 90$, and $20 / 20$ with $-1 \times 80$ in the left eye. Axial lengths were $24.35 \mathrm{~mm}$ in the right eye and $24.20 \mathrm{~mm}$ in the left eye. Slit-lamp biomicroscopy revealed corneal steepening in the inferior paracentral area in the right eye, much more evident than in the left one, and absence of Vogt's striae and Fleisher's ring in both eyes. The fundus oculi demonstrated extensive papillary and peripapillary myelination in the right eye only (fig. 1): the patch was located at the superior-inferior sectors of the optic nerve head and along the superior-inferior retinal vascular arcades masking the lower vessels. Corneal topography (Eye Top CSO, Italy) showed markedly irregular astigmatism and inferior-superior asymmetry in the right eye (fig. 2) and a focal inferonasal steepening in the left eye (fig. 3). The OCT pachymetry map scans were acquired with a high-speed anterior segment OCT prototype (Carl Zeiss Meditec Inc., Dublin, Calif., USA). The right eye was scanned and the pachymetry map was calculated. The thinnest point was $435 \mu \mathrm{m}$ in the range of 2-5 mm. Our patient showed indications for treatment with the cross-linking in her right eye.

Thirty minutes before the procedure, $2 \%$ pilocarpine drops were instilled to reduce the amount of light rays potentially harmful to the lens and retina. After topical anesthesia with two applications of lidocaine hydrochloride drops $4 \%$ and benoxinate hydrochloride $0.2 \%$ (oxybuprocaine hydrochloride), the corneal epithelium was abraded in a central, 9-mm-diameter area, using an Amoil brush. Before beginning ultraviolet A (UVA) irradiation, photosensitizing riboflavin (vitamin B2) $0.1 \%$ solution (10 mg riboflavin-5-phosphate in $10 \mathrm{ml}$ dextran $20 \%$ solution) was applied to the cornea every minute for $15 \mathrm{~min}$ to achieve adequate penetration of the solution. After the removal of the corneal epithelium and the application of riboflavin, the cornea underwent low-dose $\left(3 \mathrm{~mW} / \mathrm{cm}^{2}\right)$ irradiation with UVA lasting $30 \mathrm{~min}$; in the meantime, the use of riboflavin was repeated every $2.5 \mathrm{~min}$. After exposure to UVA the eye was medicated with antibiotic, mydriatic, anti-inflammatory eye drops and finally a bandage contact lens was inserted, which was removed at the follow-up visit after 4 days once epithelial healing was complete. Postoperatively, topical levofloxacin was given 4 times daily for 10 days, flurbiprofen sodium drops 3 times daily for 20 days and hyaluronate sodium drops $0.15 \% 6$ times daily for 45 days. In addition, our patient received oral aminoacid supplements for 10 days.

During the 6-month follow-up period, no side effect was observed. Biomicroscopic examination detected no abnormalities of corneal transparency; the fundus oculi was unchanged from the pre-operative state. Refractive and topographic control showed stabilization of the progression of keratoconus. In particular were evaluated best corrected visual acuity, apical keratometry, mean Ks, apical curvature gradient and inferior-superior index, which were comparable to preoperative data.

\section{Discussion}

To the best of our knowledge, corneal cross-linking for the treatment of keratoconus has not been previously reported in a patient with the coexistence of abnormalities in the ipsilateral posterior segment such as myelinated retinal nerve fiber layer. An association between idiopathic keratoconus and myelinated retinal nerve fiber layer has been reported in the literature [17], although it does not provide an estimate of incidence. The onset of keratoconus occurs during puberty and the disorder progresses until the third to fourth decade of life, when it usually arrests [2]. On the other hand, myelinated retinal 
nerve fibers are developmental anomalies that usually appear as congenital and stationary lesions, rarely described as being acquired or progressive [19].

In the case of our patient, the diagnosis of keratoconus was made at the age of 27 years, whereas the detection of abnormal fundus examination dates back to her childhood. The patient also reported vision worsening since school age. The decision to refer the patient to treatment with cross-linking was also derived from the stability of objective examination of the ocular fundus evaluated by comparing the retinal performed in time. Another aspect we considered was the poor visual acuity of the woman's right eye since childhood.

Schmidt et al. [20] proposed that myelinated fibers could blur retinal images and induce visual deprivation. Straatsma et al. [17] found that $10 \%$ of patients with myelinated nerve fibers have myopia, amblyopia and strabismus. The cause of amblyopia in patients with myelinated retinal nerve fibers is a matter of controversy. Some authors believe in an organic etiology and postulate that myelinated nerve fibers result in elevation of the optic disc and disorganization of neural elements leading to amblyopia [21]. In contrast, others believe that myelination does not cause organic visual loss [15]. An estimated amblyopia prevalence from 2 to 3\%, which is mainly an anisometropic amblyopia, and a $0.9 \%$ prevalence of unilateral nerve fiber layer myelination, would lead to believe the combination of these findings is more frequent [16]. In our case we can exclude anisometropic amblyopia as proved by the calculation of biometrics in the two eyes.

In this case, keratoconus treatment was also intended to maintain stable visual acuity in the right eye, already reduced in relation to the presence of ipsilateral myelinated retinal nerve fibers. Cross-linking of collagen with riboflavin $0.125 \%$ UVA is recommended for all forms of keratoconus in refractive stage (I and II) that are negatively progressing, that is to say keratoconus with a clinically, topographically, pachymetrydocumented worsening over the last 6 months. It is for such considerations that our patient was subjected to treatment.

Since the pilot study by Wollensak et al. published in January 2003 [22], there have been eight studies which have reported their efficacy results. The study methodology, in terms of inclusion and exclusion criteria, treatment parameters, outcome measures and analysis are very variable among the studies. All the studies have reported varying degrees of improvement in visual acuity, reduction in keratometry, with a progressive trend in improvement for the duration of follow-up, which was in some cases 3 years or longer. No major complications were noted, although some studies have claimed to have re-treated their non-responders [23].

The post-operative results obtained in our case are similar to those demonstrated by studies with a minimum follow-up of 6 months that indicate stabilization of progressive keratoconus after collagen cross-linking [24]. The progression of keratoconus and stability of ipsilateral myelination allowed corneal cross-linking in the right eye of our patient. Corneal cross-linking in our patient was found to be non-invasive, safe and effective. It was also important to verify the absence of postoperative changes in the fundus oculi, this being the first case of keratoconus treated in a patient with myelinated retinal nerve fiber. 


\begin{tabular}{c|l|l|l}
$\begin{array}{l}\text { Case Reports in } \\
\text { Ophthaimology }\end{array}$ & $\begin{array}{l}\text { Case Rep Ophthalmol 2011;2:99-104 } \\
\text { DOI: 10.1159/000326486 }\end{array}$ & $\begin{array}{l}\text { Published online: } \\
\text { March 8, 2011 }\end{array}$ & $\begin{array}{l}\text { O 2011 S. Karger AG, Basel } \\
\text { ISSN 1663-2699 } \\
\text { www.karger.com/cop }\end{array}$ \\
\hline
\end{tabular}

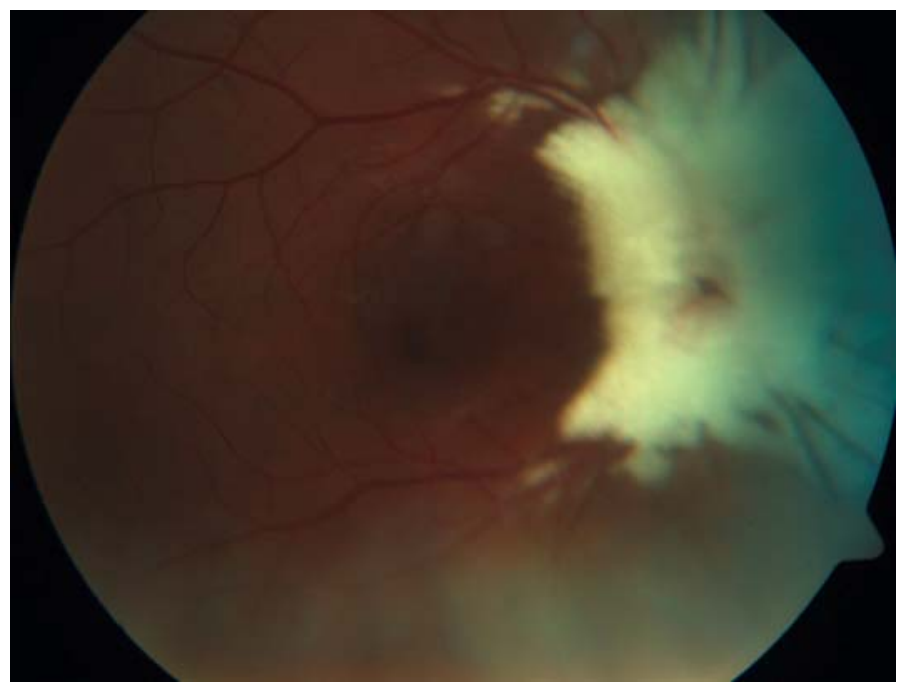

Fig. 1. Funduscopic image of the right eye showing myelinated retinal nerve fibers (FF450 plus IR fundus camera, Carl Zeiss, Germany).
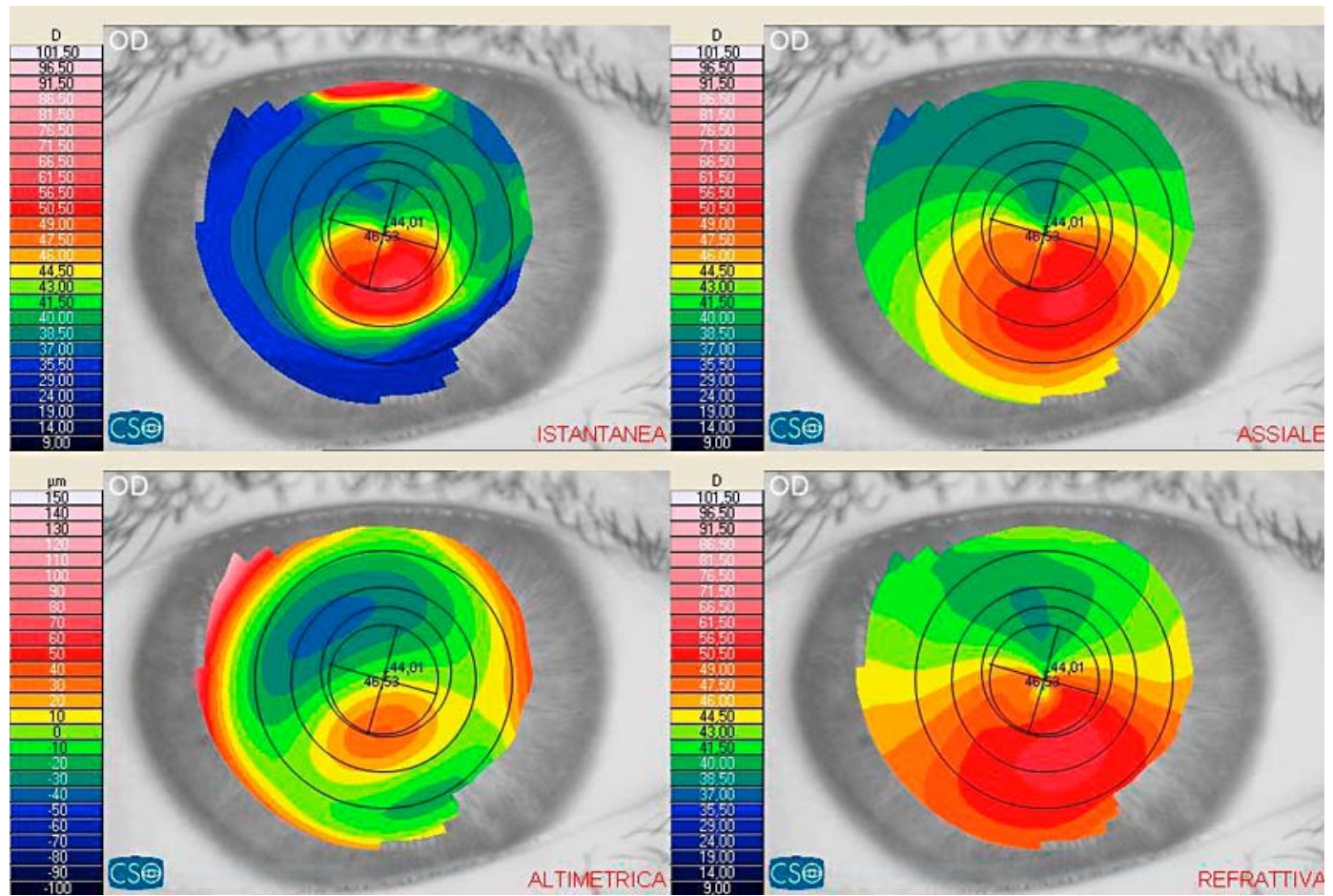

Fig. 2. Summary of topographic maps of the right eye (CM02/CM-P02 Corneal Topographer, CSO, Scandicci, Italy). 


\begin{tabular}{l|l|l|l} 
Case Reports in & $\begin{array}{l}\text { Case Rep Ophthalmol 2011;2:99-104 } \\
\text { DOI: 10.1159/000326486 }\end{array}$ & $\begin{array}{l}\text { Published online: } \\
\text { March 8, 2011 }\end{array}$ & $\begin{array}{l}\text { ○ 2011 S. Karger AG, Basel } \\
\text { ISSN 1663-2699 } \\
\text { www.karger.com/cop }\end{array}$ \\
\hline
\end{tabular}
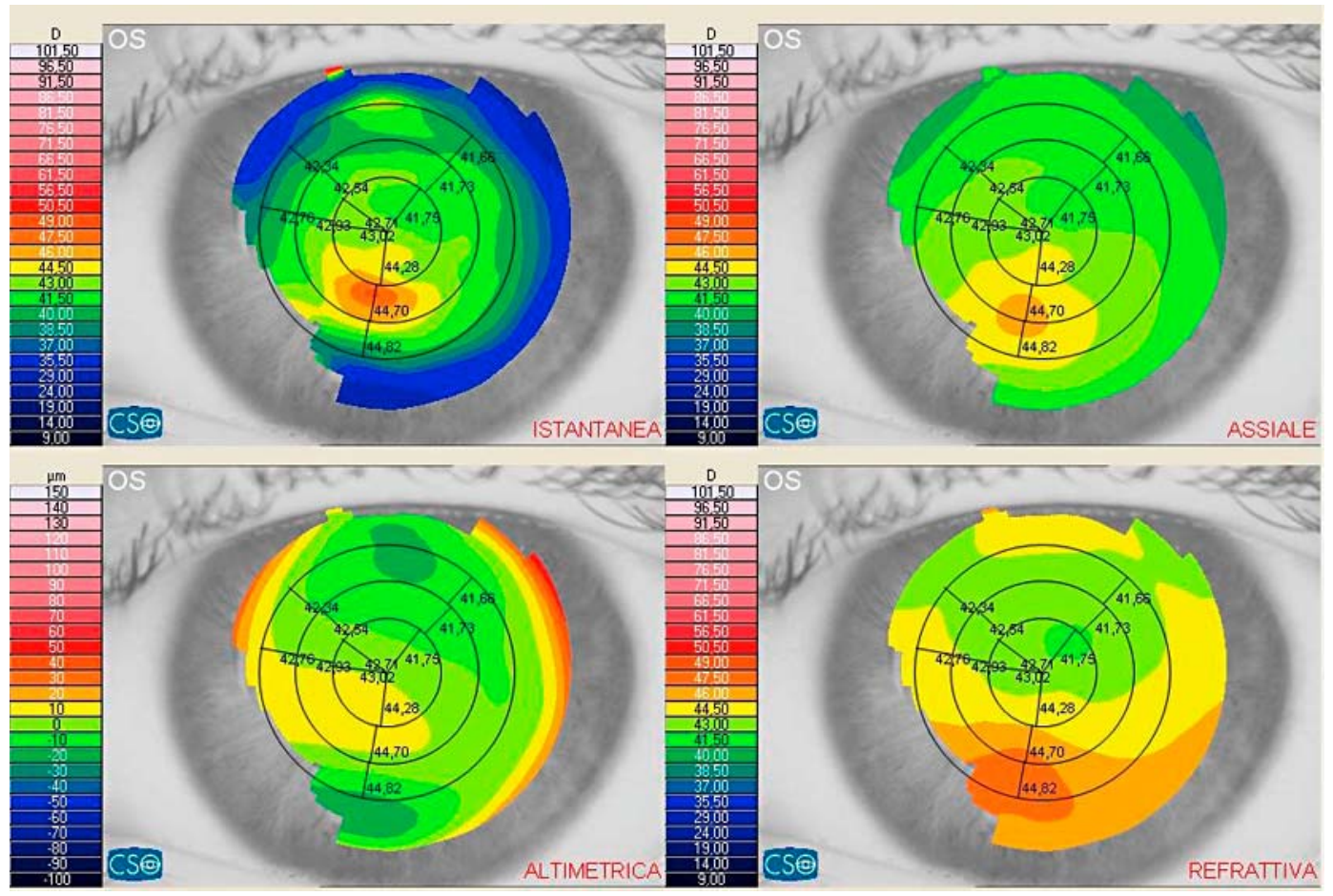

Fig. 3. Summary of topographic maps of the left eye; steepening in power map in the inferonasal quadrant.

\section{References}

1 Krachmer JH, Feder RS, Belin MW: Keratoconus and related noninflammatory corneal thinning disorders. Surv Ophthalmol 1984;28:293-322.

-2 Rabinowitz YS: Keratoconus. Surv Ophthalmol 1998;42:297-319.

3 Zhou L, Sawaguchi S, Twining SS, et al: Expression of degradative enzymes and protease inhibitors in corneas with keratoconus. Invest Ophthalmol Vis Sci 1998;39:1117-1124.

4 Udar N, Kenney MC, Chalukya M, et al: Keratoconus - no association with the transforming growth factor beta-induced gene in a cohort of American patients. Cornea 2004;23:13-17.

5 Edwards M, McGhee CN, Dean S: The genetics of keratoconus. Clin Exp Ophthalmol 2001;29:345-351.

6 Owens H, Gamble G: A profile of keratoconus in New Zealand. Cornea 2003;22:122-125.

7 Wang Y, Rabinowitz YS, Rotter JI, et al: Genetic epidemiological study of keratoconus: evidence for major gene determination. Am J Med Genet 2000;93:403-409.

-8 Forstot SL, Goldstein JH, Damiano RE, et al: Familial keratoconus. Am J Ophthalmol 1988;105:92-93.

-9 Falls HF, Allen AW: Dominantly inherited keratoconus. J Hum Genet 1969;17:317-324.

10 Freedman J, Gombos GM: Bilateral macular coloboma, keratoconus, and retinitis pigmentosa. Ann Ophthalmol 1971;3:664-665.

11 Heher KL, Traboulsi EI, Maumenee IH: The natural history of Leber's congenital amaurosis. Age-related findings in 35 patients. Ophthalmology 1992;99:241-245.

12 Leighton DA, Harris R: Retinal aplasia in association with macular coloboma, keratoconus and cataract. Clin Genet 1973;4:270-274.

13 Fogla R, Iyer GK: Keratoconus associated with cone-rod dystrophy: a case report. Cornea 2002;21:331-332.

$\checkmark 14$ Eandi CM, Del Priore LV, Bertelli E, et al: Central serous chorioretinopathy in patients with keratoconus. Retina 2008;28:94-96. 
15 Hittner HM, Antoszyk JH: Unilateral peripapillary myelinated nerve fibers with myopia and/or amblyopia. Arch Ophthalmol 1987;105:943-948.

16 Straatsma BR, Foos RY, Heckenlively JR, et al: Myelinated retinal nerve fibers. Am J Ophthalmol 1981;91: $25-38$.

17 Straatsma BR, Heckenlively JR, Foos RY, et al: Myelinated retinal nerve fibers associated with ipsilateral myopia, amblyopia, and strabismus. Am J Ophthalmol 1979;88:506-510.

-18 Ali BH, Logani S, Kristi L, et al: Progression of retinal nerve fiber myelination in childhood. Am J Ophthalmol 1994;118:515-517.

19 Jean-Louis G, Katz BJ, Digre KB, et al: Acquired and progressive retinal nerve fiber layer myelination in an adolescent. Am J Ophthalmol 2000;130:361-362.

20 Schmidt D, Meyer JH, Brandi-Dohrn J: Wide-spread myelinated nerve fibers of the optic disc: do they influence the development of myopia? Int Ophthalmol 1996-97;20:263-268.

-21 Holland PM, Anderson B Jr: Myelinated nerve fibers and severe myopia. Am J Ophthalmol 1976;81:597-599.

22 Wollensak G, Spörl E, Seiler T: Treatment of keratoconus by collagen cross linking. Ophthalmologe 2003;100: 44-49.

23 Ashwin PT, McDonnell PJ: Collagen cross-linkage: a comprehensive review and directions for future research. Br J Ophthalmol 2010;94:965-970.

24 Raiskup-Wolf F, Hoyer A, Spoerl E, et al: Collagen crosslinking with riboflavin and ultraviolet-A light in keratoconus: long-term results. J Cataract Refract Surg 2008;34:796-801. 